\title{
Effects of application parameters on spray characteristics of multi-rotor UAV
}

\author{
Hang Zhu ${ }^{1 *}$, Yu Jiang ${ }^{1}$, Hongze Li ${ }^{1}$, J unxing $\mathrm{Li}^{2}$, Huihui Zhang ${ }^{3 *}$ \\ (1. School of Mechanical and Aerospace Engineering, Jilin University, Changchun 130022, China; \\ 2. Jilin Academy of Agricultural Machinery, Changchun 130062, China; \\ 3. Water Management and Systems Research Unit, USDA-ARS, Fort Collins, CO 80526, USA)
}

\begin{abstract}
As the new favorite of agricultural plant protection operations, the spray characteristics of plant protection unmanned aerial vehicle (UAV) are the key standards to measure their quality, and the quality of spray of plant protection UAV is largely determined by the droplet drift behavior. Thus, recently, the droplet drift in the operation of plant protection UAV has been extensively studied and discussed. This paper proposes a method for studying the effects of three variables on the deposition characteristics and droplet size using a spray performance comprehensive experimental platform (developed by Jilin Agricultural Machinery Research Institute). The 12 groups of spray experiments were carried out with different combinations, rotor speed, spray height and nozzle speed and regression analysis was carried out on the obtained 12 sets of sedimentary characteristics and droplet size data to explore its effects on the deposition characteristics and droplet size. The results show that the spray height has a significant effect on the sedimentation amount, but the influence on the droplet size is negligible. The nozzle rotation speed and rotor rotation speed have a notable effect on the droplet size, but the effect on the sedimentation volume is not significant. This paper can provide theoretical basis and data support for the study of pesticide application techniques to reduce the phenomenon of droplet drift.
\end{abstract}

Keywords: droplet drift, multi-rotor UAV, experimental platform of droplet collection, laser particle size analyzer, centrifugal nozzle DOI: $10.33440 /$ j.ijpaa.20190201.0025

Citation: Zhu H, Jiang Y, Li H Z, Li J X, Zhang H H. Effects of application parameters on spray characteristics of multi-rotor UAV. Int J Precis Agric Aviat, 2019; 2(1): 18-25.

\section{Introduction}

The application of pesticides is an indispensable and crucial measure to prevent agricultural pests, Pesticide diseases, insects and grass damages avoided and recovered by pesticides worldwide account for $1 / 3$ of grain production ${ }^{[1]}$. As a major producer and consumer of pesticides, China's production and sales volume ranks first in the world, droplet drift is one of the key factors affecting the control effect of pesticides and the amount of pesticides used and the loss rate of pesticide droplets drifts from $50 \%$ to $70 \%{ }^{[2-5]}$. Therefore, the drifting behavior of fog droplets has attracted much attention in plant protection operations. Previous studies have shown that there are two internal and external conditions affecting the drift of the droplets: the internal conditions are mainly droplet size, spray device and spray technology ${ }^{[6,7]}$, and the external conditions are mainly meteorological conditions ${ }^{[8,9]}$. Currently, the methods for studying pesticide drift mainly include field tests, experimental table experiments and simulations. Since there are

Received date: 2019-10-16 Accepted date: 2019-10-20

Fund project: National Key R\&D Program of China (2016YFD0200701)

Biographies: Hang Zhu, PhD, Associate Professor, research interests: intelligent machinery of precision agriculture and automatic control, precision agricultural aviation and equipment. Mailing Address: School of Mechanical and Aerospace Engineering, Jilin University NO.5988, Renmin Street, Changchun. China, Email: hangzhu@jlu.edu.cn.

* Corresponding author: Hang Zhu, PhD, Associate Professor, research interests: precision agriculture aviation and equipment. Telephone number: +86-1808-866-5997, Email: hangzhu@jlu.edu.cn; Huihui Zhang, PhD, Research Physical Scientist, research interests: geosciences, remote sensing and sensors. Telephone number: +01-970-492-7413, Email: Huihui.Zhang@ ars.usda.gov. many environmental variables in the field test and it is difficult to completely describe the influence of air flow on spraying with simulations. Therefore, the experimental table test is widely utilized in the research of pesticide droplet drift into the advantages of high data reliability and high repeatability.

Recently, the drift of droplets in the aerial spraying process has been extensively studied and paid attention to. Many scholars have carried out a large number of experimental studies on the factors affecting drift. In [10], the use of open circuit wind tunnel and Sympatec laser diffraction analyzer proposed for the purpose of testing the droplet size, quantity and range of fan-shaped mist nozzles at different pressures, wind speeds and spray heights. The results show that the increase in the distance between the pressure, the wind speed, and the nozzle and the laser particle size analyzer results in a smaller diameter of the droplet volume of the fan-shaped mist nozzle. Thistle et al. ${ }^{[11]}$ studied the effects of factors such as wake, tip vortex, and rotor downwind on the droplet deposition using a manned fixed-wing aircraft. In [12], Thomson et al. discussed the effect of the wake wind field generated by different directions of rotation of the Air-Tractor 402B manned propulsion propeller on the droplet deposition. In [13], the flow field of multi-rotor UAV through CFD (Computational Fluid Dynamics) simulation software was simulated, and Shen Ao et al. obtained the characteristics of multi-rotor UAV flow field at different speeds through it. Nuyttens et al. ${ }^{[14]}$ established a CFD three-dimensional spray drift model, the factors such as droplet characteristics, meteorological conditions, chemical properties, canopy structure and crop characteristics were taken into account, and conducted field tests to verify that the CFD model is an auxiliary effective way to reduce the field spray lose. In [15], four kinds of spray pressure, air-blast velocity, travel speed, and three 
kinds of sampling height, were set to spray experiment and regression analysis, results showed that each spray technical parameter had significant coverage of droplet deposition in the canopy, and the degree of influence from strong to weak is sampling height, driving speed, fan outlet wind speed, and spray pressure. $\quad \mathrm{Ru}$ et al. ${ }^{[16]}$ utilized the nozzle atomization performance test system to study the influence of nozzle diameter, spray pressure and motor speed on nozzle droplet size, deposition distribution, spray width and power consumption, results showed the motor voltage has a more significant effect on the droplet size than the nozzle diameter and spray pressure parameters. There are many studies on the performance of the nozzle itself, however, few studies on the influence of the spray drift on the rotor wind field of the UAV which is essential to spray drift and influent spray quality deeply has been reported.

In this paper, the droplet collection experimental table was used to examine the droplet deposition amount and droplet size of the UAV equipped with the centrifugal nozzle at distinct spray heights, nozzle speeds, and rotor speeds. The analysis of the influence of application parameters on the droplet deposition of centrifugal nozzles is expected to provide theoretical basis and data support for the study of pesticide application techniques to reduce droplet drift.

\section{The structure and working principle of the comprehensive experimental platform of droplet collection}

The comprehensive experimental platform of droplet collection for spray performance used in this paper was developed by Jilin Agricultural Machinery Research Institute. The mechanical structure and working principle are as follows.

\subsection{Mechanical structure}

As shown in Figure 1, comprehensive experimental platform of droplet collection includes: main frame, U-shaped fog trough, ultrasonic liquid level test vehicle, gantry truss, test tube rack and turnover system. The experimental platform has a total length of $5 \mathrm{~m}$, a width of $2.4 \mathrm{~m}$ and a height of $1.2 \mathrm{~m}$. The U-shaped fog trough opening is $50 \mathrm{~mm}, 100$ uniform distribution. The gantry truss is utilized to fix the UAV, and the height of the truss is adjusted by the motor drive chain to control the flying height of the $\mathrm{UAV}_{\text {operation }}{ }^{[17]}$.

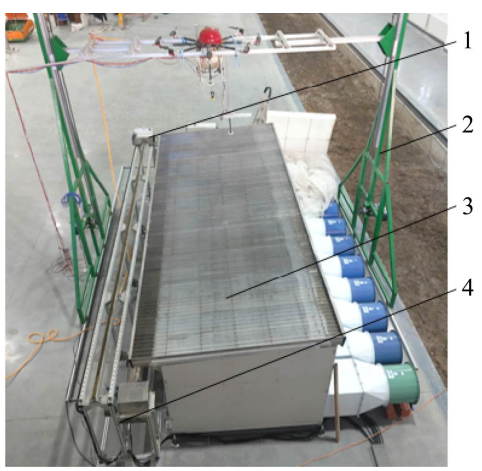

a. Experiment platform

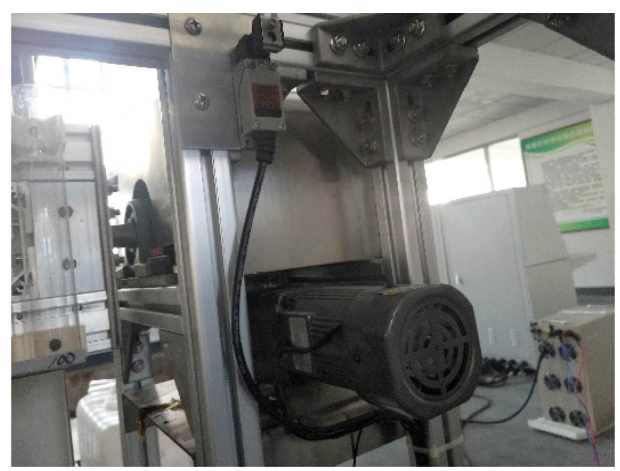

b. Turnover system

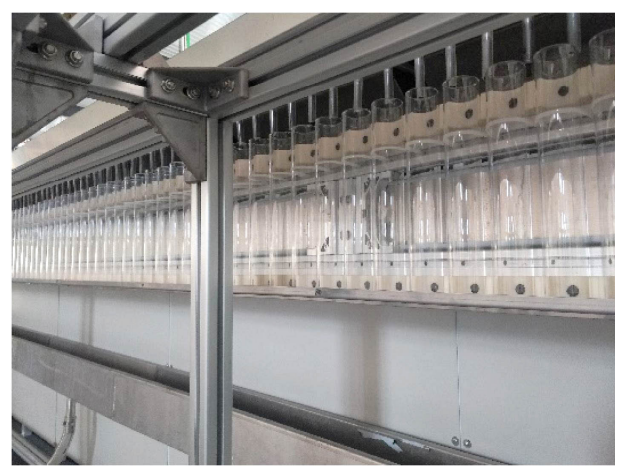

c. Test tube rack

1. Gantry truss 2. U-shaped fog trough 3. Ultrasonic liquid level test vehicle 4. Main frame

Figure 1 Comprehensive experimental platform of droplet collection

Since the trough has an inclination of $7^{\circ}$, the liquid collected in each trough will flow into the front of end tube. After the end of the spray, the photoelectric positioning coupling switch coordinated with the ultrasonic level test vehicle moving in the independent frame are used to measure the liquid level height of each test tube. After the measurement, the tube rack turnover system dumps the liquid in each tube to complete the measurement. Change the operating parameters and proceed to the next set of measurements.

\subsection{Control system}

The control of the ultrasonic liquid level test vehicle, the test tube rack turnover mechanism and the fan start and stop is realized through the programmable logic controller (PLC). The working principle is shown in Figure 2. The PLC communicates with the computer through the RS232 serial port. The host computer is programmed by LabVIEW 2013 (NI, Texas, USA, 253000). The front panel of the program is shown in Figure 3. The ultrasonic liquid level test vehicle, the fixed lifting structure of the UAV, and the turnover mechanism of the test tube rack can all be controlled by the PLC controller.

\section{Spray equipment and experiment design}

\subsection{Spray equipment}

As shown in Figure 4, the spraying device consists of a rotor planting UAV (NJY-1206) equipped with a medical kit, a pump and a centrifugal nozzle. The UAV diagonal rotor distance is $1.2 \mathrm{~m}$, the driving mode is electric $24 \mathrm{~V}$, the medical kit capacity is $10 \mathrm{~L}$, and the pump pressure is $0.2 \mathrm{MPa}$. The rotor plant protection UAV can change the surrounding wind field strength by adjusting the rotor speed, which can be utilized to simulate the wind field during the actual flight of the UAV and the flow deposition characteristics of the UAV at the fixed point can be measured. The spray equipment adopts the centrifugal nozzle PGP-ADG2 (developed by Jilin Agricultural Machinery Research Institute), and the two nozzles are respectively fixed directly below the rotor, the spacing is $120 \mathrm{~cm}$.

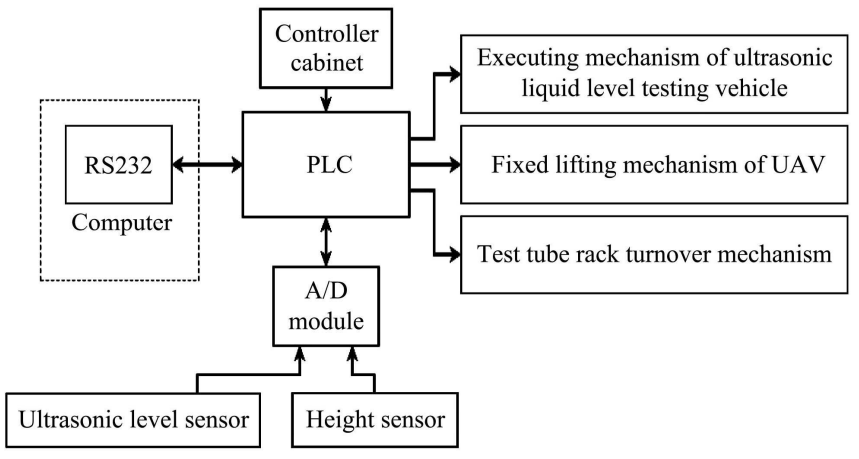

Figure 2 Principle of electrical control 


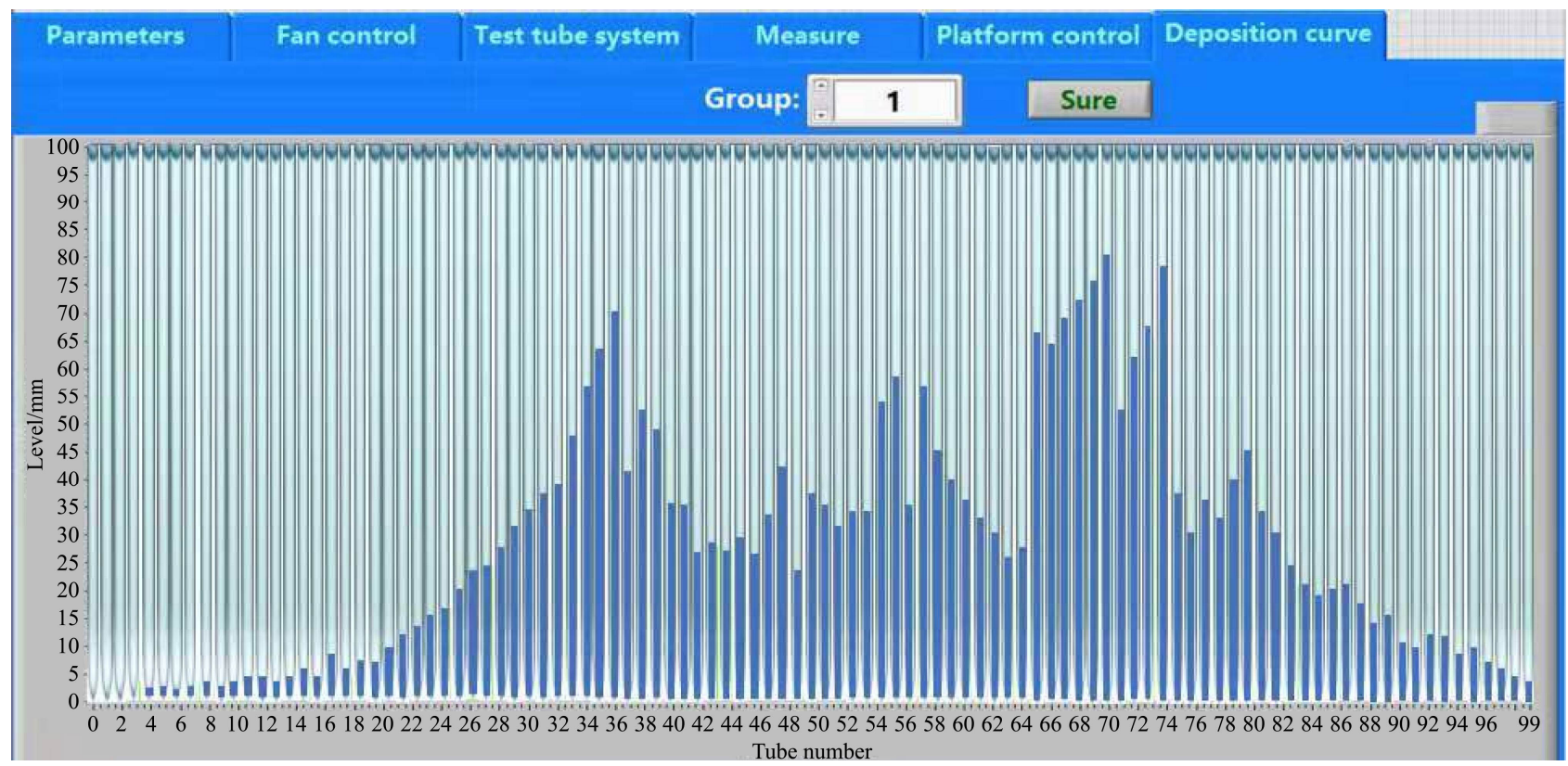

Figure 3 Front panel of LabVIEW

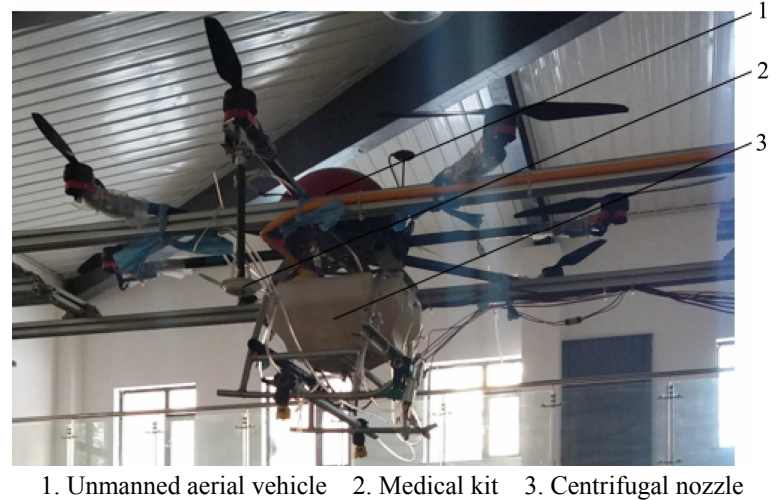

Figure 4 Spray equipment

\subsection{Experiment design}

The test was carried out indoors. The room temperature was constant during the experiment. The temperature was $13 \sim 21^{\circ} \mathrm{C}$, humidity was $18.2 \% \sim 26.5 \%$, and wind speed was $0 \mathrm{~m} / \mathrm{s}$, each experiment was conducted by selecting clean water as the experimental medium. A series of experiments were performed by combining the three variables in Table 1 .

Table 1 Parameters of variates

\begin{tabular}{ccc}
\hline Rotor speed $/ \mathrm{r} \cdot \mathrm{min}^{-1}$ & Spray height $/ \mathrm{m}$ & Nozzle speed $/ \mathrm{r} \cdot \mathrm{min}^{-1}$ \\
\hline \multirow{2}{*}{3060} & 0.8 & 9250 \\
\hline 4500 & 1.5 & 11750 \\
\hline
\end{tabular}

(1) Spray height

The actual spray height was simulated by adjusting the relative distance between the fixed UAV and the U-shaped fog trough, and the experiment was carried out under the spray height of $0.8 \mathrm{~m}$ and $1.5 \mathrm{~m}$ to analyze the effect of spray height on the droplet deposition characteristics.

(2) Nozzle speed

In the actual spraying process, assuming that the droplet of the large particle size, it has large kinetic energy, and hard to drift with the wind and evaporate, but it is prone to bounce and roll loss (called loss in the field), causing the loss of liquid medicine, poor spray effect, and the environment pollution meanwhile, the droplet of the small particle size can be well settled and covered on the surface of the crop, and the adhesion performance is favorable, the loss is hard to occur, and the utilization rate of the pesticide is high, in addition, the fine mist droplet has excellent penetrating ability and the control effect is remarkable, yet, too tiny droplets are greatly affected by the airflow, are prone to drift, pollute the environment, and may cause serious phytotoxicity to crops in adjacent areas ${ }^{[18]}$. Consequently, the particle size of the pesticide droplets is too large or too small to obtain a satisfactory spray effect. It has been shown that the centrifugal nozzle speed directly affects the particle size of the droplets, and the droplet diameter of the centrifugal nozzle is between $100 \sim 150 \mu \mathrm{m}$ at 9000-12000 r/min, which achieves the best spray quality ${ }^{[19]}$. In this experiment, the speed of the centrifugal nozzle was controlled by PWM (Pulse Width Modulation) signal controller. The influence of nozzle rotation speed on droplet deposition characteristics was analyzed by the experiment conducted under the conditions of nozzle rotation speed of $9250 \mathrm{r} / \mathrm{min}, 11750 \mathrm{r} / \mathrm{min}$ and $12500 \mathrm{r} / \mathrm{min}$.

\section{(3) Rotor speed}

The blade pitch of the rotorcraft is fixed so it balances the gravity by changing the rotor speed to reach the hovering state. The rotor UAV applied in this experiment has a take-off weight of $20 \mathrm{~kg}$ at full load, the corresponding rotor speed is $4500 \mathrm{r} / \mathrm{min}$, the take-off weight is $10 \mathrm{~kg}$ at no load, and the corresponding rotor speed is $3060 \mathrm{r} / \mathrm{min}$. To simulate the two hovering states of the $\mathrm{UAV}$, the influence of rotor speed on droplet deposition characteristics was analyzed by experiment conducted under the condition of rotor speed of $3060 \mathrm{r} / \mathrm{min}$ and $4500 \mathrm{r} / \mathrm{min}$.

Under the influence of the above three factors, the specific test parameters are determined as shown in Table 2.

\subsubsection{Measurement of droplet deposition}

Run the experimental platform, adjust the spray device to the optimal position: directly over the platform, and start the $5 \mathrm{~min}$ simulation spray. After the spray, the test tube deposition amount is measured by the ultrasonic liquid level test vehicle, repeat the above steps until the actual deposition amount of all 12 groups of experiments was obtained, and repeat each experiment three times. Since the spray apply double nozzle, so theoretical deposition amount is calculated as 
Table 2 Total variates

\begin{tabular}{|c|c|c|c|c|c|c|}
\hline \multirow{4}{*}{$\begin{array}{l}\text { Spray height } \\
/ \mathrm{m}\end{array}$} & \multicolumn{6}{|c|}{ Rotor speed $/ \mathrm{r} \cdot \min ^{-1}$} \\
\hline & \multicolumn{3}{|c|}{3060} & \multicolumn{3}{|c|}{4500} \\
\hline & \multicolumn{6}{|c|}{ Nozzle speed $/ \mathrm{r} \cdot \min ^{-1}$} \\
\hline & 9250 & 11750 & 12500 & 9250 & 11750 & 12500 \\
\hline 0.8 & $\mathrm{E}_{11}$ & $\mathrm{E}_{12}$ & $\mathrm{E}_{13}$ & $\mathrm{E}_{21}$ & $\mathrm{E}_{22}$ & $\mathrm{E}_{23}$ \\
\hline 1.5 & $\mathrm{~F}_{11}$ & $\mathrm{~F}_{12}$ & $\mathrm{~F}_{13}$ & $\mathrm{~F}_{21}$ & $\mathrm{~F}_{22}$ & $\mathrm{~F}_{23}$ \\
\hline
\end{tabular}

Description of variables:

(1) $\mathrm{E}$ and $\mathrm{F}$ represent two levels of different spray heights: $\mathrm{E}$ for $0.8 \mathrm{~m}$ and $\mathrm{F}$ for $1.5 \mathrm{~m}$;

(2) The first digits 1 and 2 after the letter represent the two levels of rotor speed: 1 for $3060 \mathrm{r} / \mathrm{min}$ and 2 for $4500 \mathrm{r} / \mathrm{min}$

(3) The last digits 1, 2 and 3 represent the three levels of nozzle speed: 1 for $9250 \mathrm{r} / \mathrm{min}, 2$ for $11750 \mathrm{r} / \mathrm{min}$ and 3 for $12500 \mathrm{r} / \mathrm{min}$.

$$
D=2 q \cdot t
$$

where, $D$ is theoretical deposition; $q$ is nozzle flow and $q=$ $0.31 \mathrm{~L} / \mathrm{min}, t=5 \mathrm{~min}$. The theoretical deposition amount was calculated to be $3.1 \mathrm{~L}$. The effective deposition rate of the drug solution is given by the equation

$$
E=D e / D \times 100 \%
$$

where, $E$ is effective deposition rate; $D e$ is effective deposition amount. The coefficient of variation $C V$ is a crucial indicator to measure the uniformity of droplet distribution which is given by

$$
C V=S D / X \times 100 \%
$$

where, $S D$ is standard deviation; $X$ is average.

\subsubsection{The measurement of droplet particle size}

With the development of electronic and optical technology, the laser particle size analyzer can directly measure the droplet size, and the computer image analysis system can be used to measure and analyze the diameter of the droplet and the uniformity of the spray distribution. Laser particle size analyzer has been widely applied in plant protection spray experiment ${ }^{[20,21]}$. Results show that the laser particle size analyzer has significant advantages and excellent effects in the application of plant protection spray experiment. In this test, the DP-02 laser particle size analyzer was utilized to measure and analyze the effects of spray height, motor speed and rotor speed on the droplet size. The laser particle size analyzer was mounted directly below the nozzle, and after the optical components were properly focused, the sample was measured against the background of measuring particle-free dispersion media. Make sure that there is enough measurement time to gather sufficient signals to guarantee that results are statistically representative ${ }^{[22]}$. The particle size of the droplet refers to the size of the space occupied by the droplet, generally, the parameter applied to analyze the droplet is: the droplet diameter $\mathrm{D}_{\mathrm{V} 10}$ whose droplets cumulative distribution is $10 \%$, that is, the volume of the droplet is smaller than the parameter occupy $10 \%$ of the total volume of the droplets; the droplet diameter $\mathrm{D}_{\mathrm{V} 50}$ whose droplets cumulative distribution is $50 \%$, that is, the volume of the droplets smaller than the diameter of the droplets accounts for $50 \%$ of the total volume of the droplets, also known as volume median diameter (VMD); the droplet diameter $\mathrm{D}_{\mathrm{V} 90}$ whose droplets cumulative distribution is $90 \%$, that is, the volume of the droplets smaller than the diameter of the droplets accounts for $90 \%$ of the total volume of the droplets ${ }^{[23,24]}$. As an index for evaluating the uniformity of the droplet size, the width of the fog droplet spectrum can directly reflect the distribution of the diameter of the droplet whose calculation formula is:

$$
\text { R.S. }=\left(D_{V 90}-D_{V 10}\right) / D_{V 50}
$$

where, R.S. is the width of the fog droplet spectrum; $D_{V 90}$ is $90 \%$ by volume medium diameter; $D_{V 10}$ is $10 \%$ volume medium diameter, and $D_{V 50}$ is $50 \%$ volume medium diameter.

\section{Results and analysis}

\subsection{Effect of dissimilar spray parameters on droplet deposition}

The theoretical deposition amount, effective deposition amount and effective utilization rate of different groups are shown in Table 3. All the theoretical deposition amount is $3100 \mathrm{~mL}$, the effective deposition amount is between 1174.9 and $2303.3 \mathrm{~mL}$, effective deposition rate is between $37.9 \%$ and $74.3 \%$, it can be seen that the overall effective deposition rate of the spray is less than $75 \%$.

Table 3 Deposition characteristic of each group

\begin{tabular}{ccccc}
\hline Group & $\begin{array}{c}\text { Theoretical } \\
\text { deposition } \\
\text { amount/mL }\end{array}$ & $\begin{array}{c}\text { Effective } \\
\text { deposition } \\
\text { amount } / \mathrm{mL}\end{array}$ & $\begin{array}{c}\text { Effective } \\
\text { deposition } \\
\text { rate/\% }\end{array}$ & $\begin{array}{c}\text { Coefficient of } \\
\text { variation/\% }\end{array}$ \\
\hline $\mathrm{E}_{11}$ & 3100 & $1174.9 \pm 551.6$ & $37.9 \pm 30.3$ & $52.4 \pm 15.0$ \\
$\mathrm{E}_{12}$ & 3100 & $1745.0 \pm 165.4$ & $56.3 \pm 8.3$ & $46.7 \pm 6.1$ \\
$\mathrm{E}_{13}$ & 3100 & $2139.9 \pm 173.0$ & $69.0 \pm 2.3$ & $43.4 \pm 2.6$ \\
$\mathrm{E}_{21}$ & 3100 & $2303.3 \pm 232.8$ & $74.3 \pm 8.2$ & $42.6 \pm 8.2$ \\
$\mathrm{E}_{22}$ & 3100 & $1894.0 \pm 226.0$ & $61.1 \pm 6.5$ & $42.1 \pm 4.9$ \\
$\mathrm{E}_{23}$ & 3100 & $2147.0 \pm 208.9$ & $69.3 \pm 10.5$ & $41.6 \pm 1.2$ \\
$\mathrm{~F}_{11}$ & 3100 & $1624.3 \pm 348.4$ & $52.4 \pm 17.1$ & $52.4 \pm 12.2$ \\
$\mathrm{~F}_{12}$ & 3100 & $1888.7 \pm 188.3$ & $60.9 \pm 9.1$ & $50.7 \pm 6.7$ \\
$\mathrm{~F}_{13}$ & 3100 & $1595.5 \pm 353.6$ & $51.5 \pm 16.7$ & $50.7 \pm 5.3$ \\
$\mathrm{~F}_{21}$ & 3100 & $1820.2 \pm 247.6$ & $58.7 \pm 8.8$ & $49.3 \pm 2.4$ \\
$\mathrm{~F}_{22}$ & 3100 & $1959.0 \pm 255.9$ & $63.2 \pm 1.1$ & $49.4 \pm 2.3$ \\
$\mathrm{~F}_{23}$ & 3100 & $1895.5 \pm 513.3$ & $61.1 \pm 12.1$ & $49.8 \pm 6.0$ \\
\hline
\end{tabular}

\subsubsection{Rotor speed effect}

Explore the deposition characteristics of the rotor speeds of $3060 \mathrm{r} / \mathrm{min}$ and $4500 \mathrm{r} / \mathrm{min}$ in the conditions that the nozzle speed $(12500 \mathrm{r} / \mathrm{min})$ and spray height $(1.5 \mathrm{~m})$ were set to constant. The droplet deposition of two groups of $F_{13}$ and $F_{23}$ under the influence of rotor speed is shown in Figure 5.

As the rotor speed increases, the uniformity of the droplet coverage is improved, but the droplet deposition rate is lower. The amount of droplet deposition is between 0 and $70 \mathrm{~mL}$, and the sedimentation line is roughly in the shape of a quadratic parabola ${ }^{[25-27]}$. The two peaks are directly below the two nozzles, and the valley is just below the midpoint of the two nozzles. As can be seen from Table 3 above, the effective deposition rate of $E_{13}$ is $69.0 \%$, the effective deposition rate of $\mathrm{E}_{23}$ is $69.3 \%$, the deposition rate increases when the rotation speed increases at $0.8 \mathrm{~m}$ height, and the effective deposition rate of $\mathrm{F}_{13}$ is $51.5 \%$. The effective deposition rate of $\mathrm{F}_{23}$ is $61.1 \%$, the deposition rate increases when the rotation speed increases at $1.5 \mathrm{~m}$ height, and it can be seen that the rotor speed and the effective deposition rate are not related.

\subsubsection{Nozzle speed effect}

Investigated the deposition characteristics of the nozzle speeds of $9250 \mathrm{r} / \mathrm{min}, 11750 \mathrm{r} / \mathrm{min}$ and $12500 \mathrm{r} / \mathrm{min}$ under the rotor speed $(3060 \mathrm{r} / \mathrm{min})$ and spray height $(1.5 \mathrm{~m})$ were set to constant. The droplet deposition of $F_{11}, F_{12}$ and $F_{13}$ under the influence of rotor speed is shown in Figure 6.

As the nozzle speed increases, the variation of the droplets uniformity and the drift phenomenon is not obvious. The droplet deposition amount is between 0 and $80 \mathrm{ml}$, and the sedimentation fold line is roughly in the shape of a quadratic parabola. The two peaks are directly below the two nozzles, and the trough is just 
below the midpoint of the two nozzles. As can be seen from Table 3 above, the effective deposition rate of $F_{11}$ is $52.4 \%$, the effective deposition rate of $\mathrm{F}_{12}$ is $60.9 \%$, and the effective deposition rate of $\mathrm{F}_{13}$ is $51.5 \%$. The results above showed that the

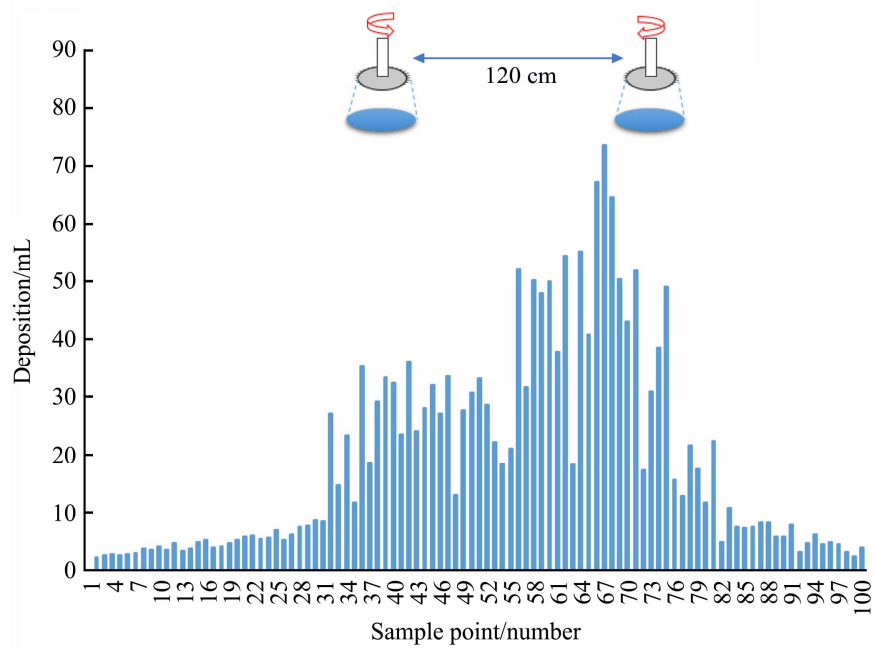

Spray height: $1.5 \mathrm{~m}$; Nozzle speed: $12500 \mathrm{r} \cdot \mathrm{min}^{-1}$; Rotor speed: $3060 \mathrm{r} \cdot \mathrm{min}^{-1}$ a. $\mathrm{F}_{13}$ nozzle rotation speed is not related to the effective deposition rate which was associate with the conclusion illustrated in [28]: when the horizontal wind speed constant, the theoretical drift rate and actual drift rate were as the rotational speed increases.

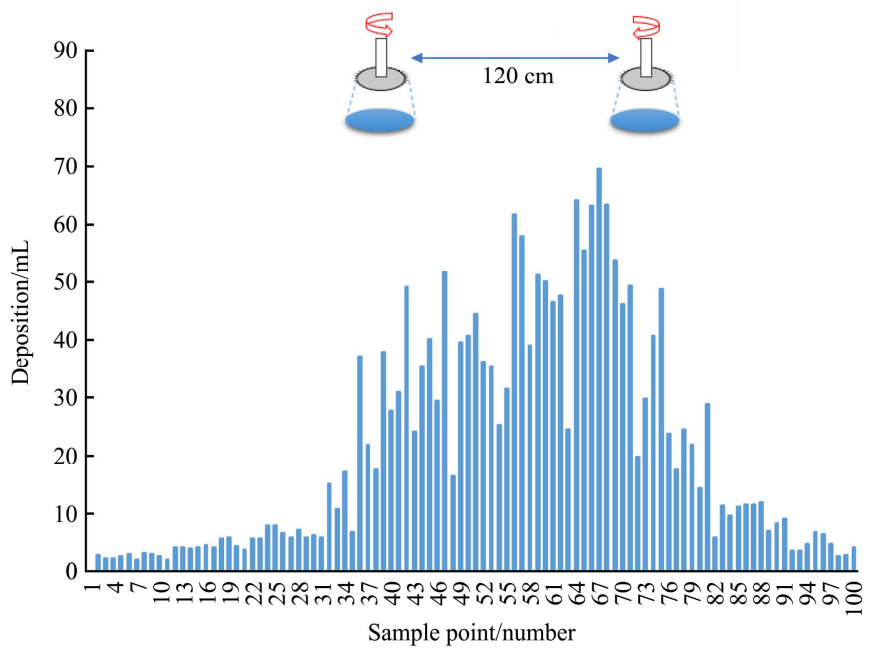

Spray height: $1.5 \mathrm{~m}$; Nozzle speed: $12500 \mathrm{r} \cdot \mathrm{min}^{-1}$; Rotor speed: $4500 \mathrm{r} \cdot \mathrm{min}^{-1}$ b. $\mathrm{F}_{23}$

Figure 5 Line chart of droplet deposition in different rotor speed

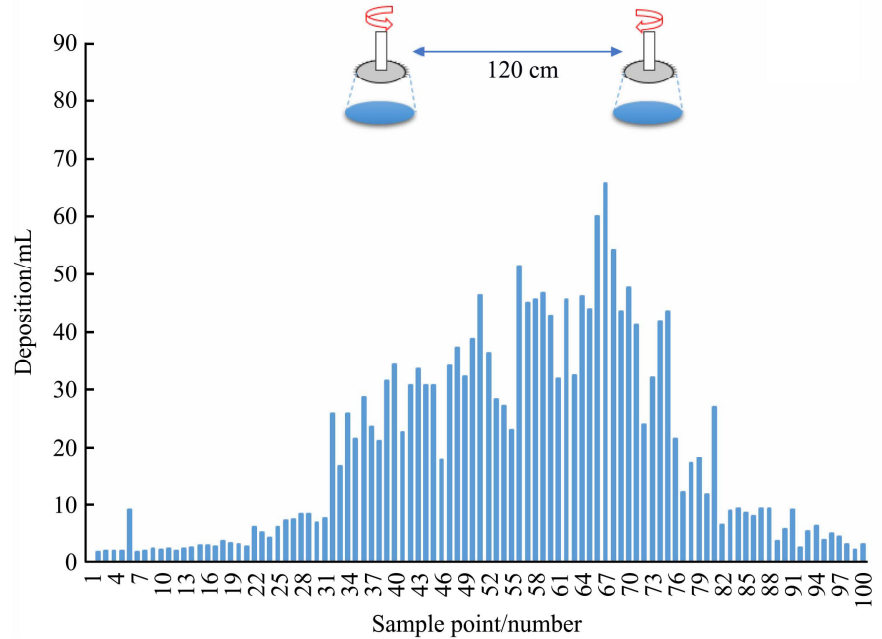

Spray height: $1.5 \mathrm{~m}$; Nozzle speed: $9250 \mathrm{r} \cdot \mathrm{min}^{-1}$; Rotor speed: $3060 \mathrm{r} \cdot \mathrm{min}^{-1}$

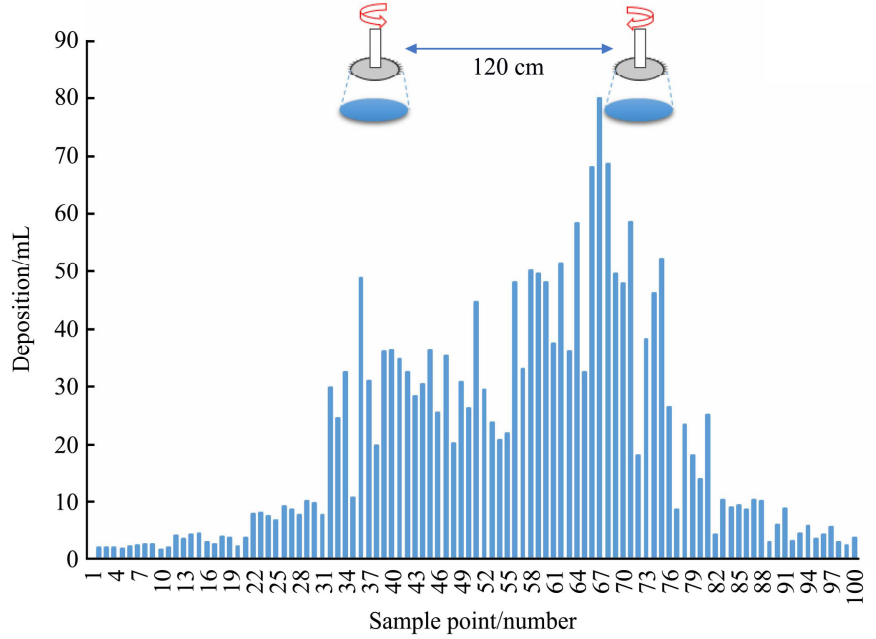

Spray height: $1.5 \mathrm{~m}$; Nozzle speed: $11750 \mathrm{r} \cdot \mathrm{min}^{-1}$; Rotor speed: $3060 \mathrm{r} \cdot \mathrm{min}^{-1}$

$$
\text { a. } \mathrm{F}_{11}
$$

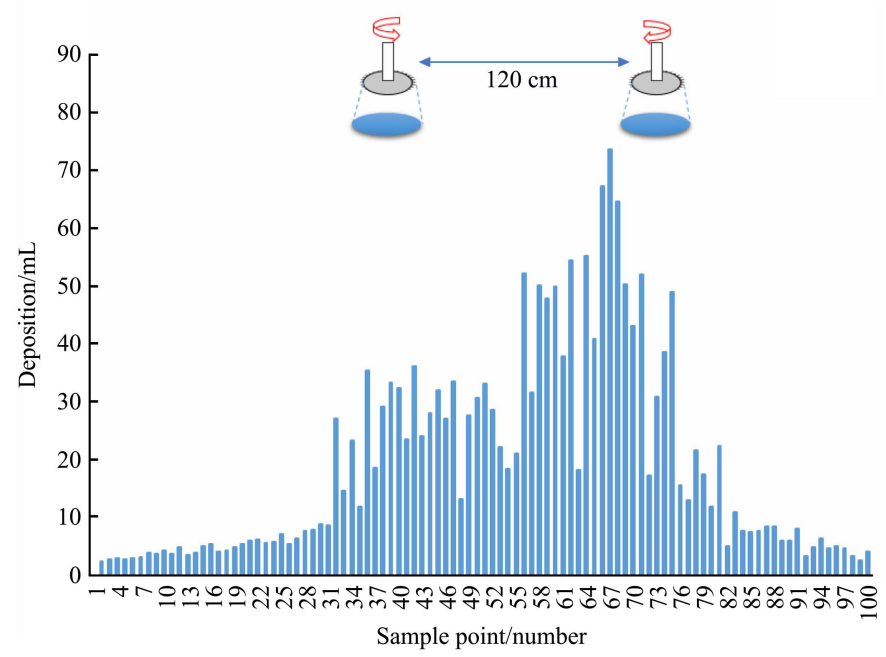

Spray height: $1.5 \mathrm{~m}$; Nozzle speed: $12500 \mathrm{r} \cdot \mathrm{min}^{-1}$; Rotor speed: $3060 \mathrm{r} \cdot \mathrm{min}^{-1}$

$$
\text { c. } \mathrm{F}_{13}
$$

Figure 6 Line chart of droplet deposition in different nozzle speed 


\subsubsection{Spray height effect}

The rotor speed $(4500 \mathrm{r} / \mathrm{min})$ and the nozzle speed (12500 r/min) were set to constant, and the deposition characteristics were investigated at a spray height of $0.8 \mathrm{~m}$ and $1.5 \mathrm{~m}$. The droplet deposition of $\mathrm{E}_{23}$ and $\mathrm{F}_{23}$ under the influence of rotor speed is shown in Figure 7.

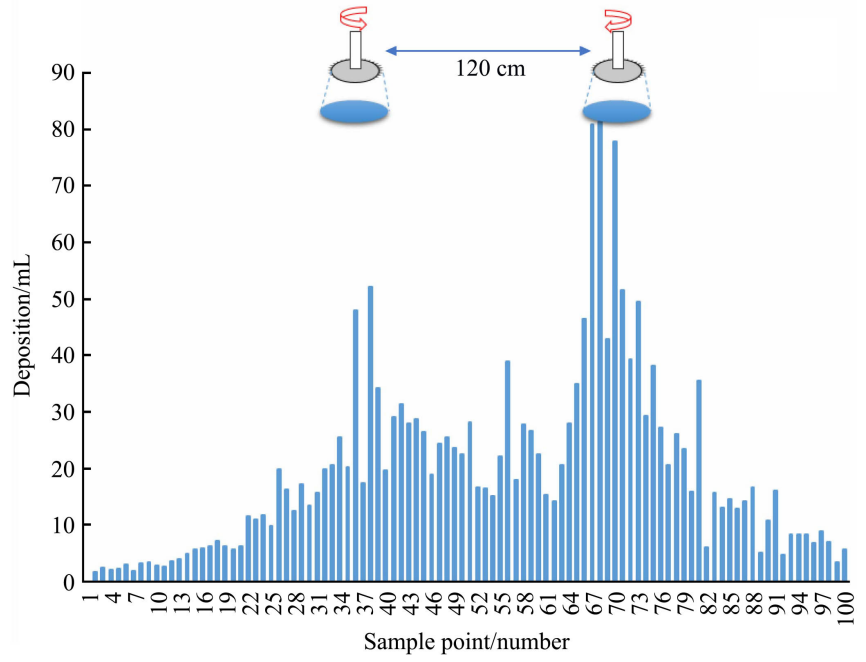

Spray height: $0.8 \mathrm{~m}$; Nozzle speed: $12500 \mathrm{r} \cdot \mathrm{min}^{-1}$; Rotor speed: $4500 \mathrm{r} \cdot \mathrm{min}^{-1}$ a. $\mathrm{E}_{23}$

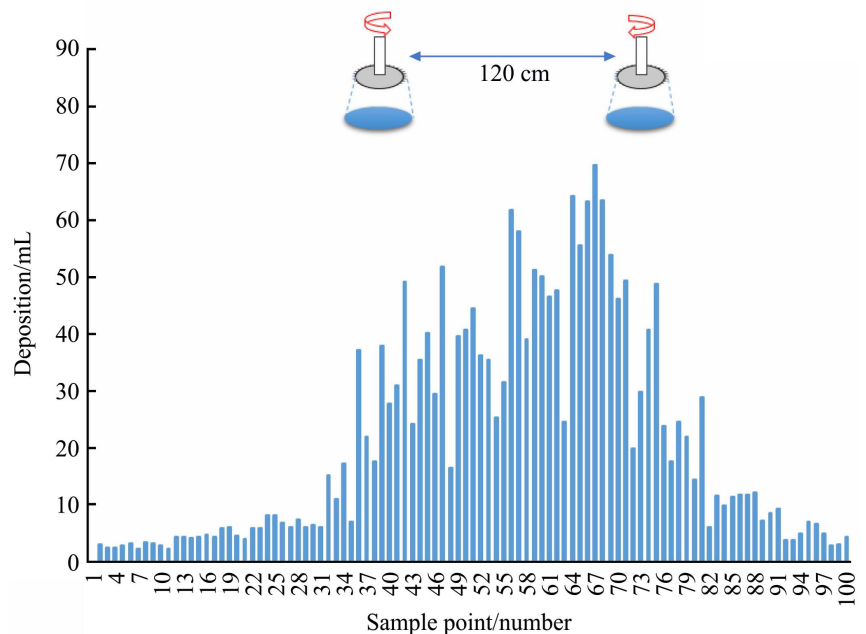

Spray height: $1.5 \mathrm{~m}$; Nozzle speed: $12500 \mathrm{r} \cdot \mathrm{min}^{-1}$; Rotor speed: $4500 \mathrm{r} \cdot \mathrm{min}^{-1}$ b. $\mathrm{F}_{23}$

Figure 7 Line chart of droplet deposition in different spray height

As the spray height increases, the uniformity of the droplets improves, but the drift phenomenon is more evident. The amount of droplet deposition is between 0 and $85 \mathrm{~mL}$, and the sedimentation line is roughly in the shape of a quadratic parabola. The two peaks are directly below the two nozzles, and the trough is near the midpoint of the two nozzles. As can be seen from Table 3 , the effective deposition rate of $E_{23}$ is $69.3 \%$, and the effective deposition rate of $\mathrm{F}_{23}$ is $61.1 \%$. The increase of spray height leads to a decrease in effective deposition rate, clearly, negative correlation between the two.

\subsection{Effect of distinct spray parameters on droplet size}

The particle size of each group is shown in Table 4. The droplet diameter $\mathrm{D}_{\mathrm{V} 50}$ ranges from 119.39 to $132.92 \mu \mathrm{m}$, and R.S., the width of the fog droplet spectrum ranges from 0.82 to 0.89 .

\subsubsection{Rotor speed effect}

Set the nozzle speed $(12500 \mathrm{r} / \mathrm{min})$ and spray height $(1.5 \mathrm{~m})$ to constant, and explore the particle size when the rotor speed is
$3060 \mathrm{r} / \mathrm{min}$ and $4500 \mathrm{r} / \mathrm{min}$ respectively. As shown in Table 4 , the $\mathrm{F}_{13}$ group had a $\mathrm{D}_{\mathrm{V} 10}$ of $75.75 \mu \mathrm{m}$, a $\mathrm{D}_{\mathrm{V} 50}$ of $127.72 \mu \mathrm{m}$, a $\mathrm{D}_{\mathrm{V} 90}$ of $183.70 \mu \mathrm{m}$, the $\mathrm{F}_{23}$ group of $\mathrm{D}_{\mathrm{V} 10}$ of $72.21 \mu \mathrm{m}$, a $\mathrm{D}_{\mathrm{V} 50}$ of $119.55 \mu \mathrm{m}$ and a $\mathrm{D}_{\mathrm{V} 90}$ of $174.94 \mu \mathrm{m}$. Comparing the particle size of the two groups, it is known that the particle size of the $F_{23}$ group is significantly smaller than that of the $F_{13}$ group, that is, as the rotation speed of the rotor increases, the droplet size decreases, so the two are negatively correlated.

Table 4 Droplet diameter of each group

\begin{tabular}{ccccc}
\hline Group & $D_{\mathrm{V} 10} / \mu \mathrm{m}$ & $D_{\mathrm{V} 50} / \mu \mathrm{m}$ & $D_{\mathrm{V} 90} / \mu \mathrm{m}$ & R.S. \\
\hline $\mathrm{E}_{11}$ & 87.75 & 128.92 & 199.58 & 0.87 \\
$\mathrm{E}_{12}$ & 78.32 & 127.95 & 190.34 & 0.88 \\
$\mathrm{E}_{13}$ & 78.91 & 130.74 & 189.06 & 0.84 \\
$\mathrm{E}_{21}$ & 78.29 & 132.92 & 193.11 & 0.86 \\
$\mathrm{E}_{22}$ & 79.63 & 131.68 & 196.85 & 0.89 \\
$\mathrm{E}_{23}$ & 70.81 & 120.36 & 178.08 & 0.89 \\
$\mathrm{~F}_{11}$ & 79.04 & 131.59 & 188.90 & 0.82 \\
$\mathrm{~F}_{12}$ & 78.16 & 130.45 & 186.93 & 0.83 \\
$\mathrm{~F}_{13}$ & 75.75 & 127.72 & 183.70 & 0.84 \\
$\mathrm{~F}_{21}$ & 72.75 & 122.85 & 178.39 & 0.86 \\
$\mathrm{~F}_{22}$ & 70.97 & 119.39 & 171.96 & 0.85 \\
$\mathrm{~F}_{23}$ & 72.21 & 119.55 & 174.94 & 0.86 \\
\hline
\end{tabular}

4.2.2 Nozzle speed effect

Set the rotor speed $(3060 \mathrm{r} / \mathrm{min})$ and spray height $(1.5 \mathrm{~m})$ as constants to investigate the particle size under the conditions that the nozzles speed is $9250 \mathrm{r} / \mathrm{min}, 11750 \mathrm{r} / \mathrm{min}$ and $12500 \mathrm{r} / \mathrm{min}$ respectively. $\quad F_{11}$ group $D_{\mathrm{V} 10}$ is $79.04 \mu \mathrm{m}, \mathrm{D}_{\mathrm{V} 50}$ is $131.59 \mu \mathrm{m}$, $\mathrm{D}_{\mathrm{V} 90}$ is $188.90 \mu \mathrm{m}, \mathrm{F}_{12}$ group $\mathrm{D}_{\mathrm{V} 10}$ is $78.16 \mu \mathrm{m}, \mathrm{D}_{\mathrm{V} 50}$ is $130.45 \mu \mathrm{m}$, $\mathrm{D}_{\mathrm{V} 90}$ is $186.93 \mu \mathrm{m}, \mathrm{F}_{13}$ group $\mathrm{D}_{\mathrm{V} 10}$ is $75.75 \mu \mathrm{m}, \mathrm{D}_{\mathrm{V} 50}$ is $127.72 \mu \mathrm{m}$, and $\mathrm{D}_{\mathrm{V} 90}$ is $183.70 \mu \mathrm{m}$. Comparing the particle size of the three groups, the particle size of $F_{11}, F_{12}$ and $F_{13}$ is gradually reduced, that is, the droplet size decreases with the increase of the nozzle speed, and the two are negatively correlated.

\subsubsection{Spray height effect}

Investigate the particle size of the spray heights of $0.8 \mathrm{~m}$ and $1.5 \mathrm{~m}$ respectively under the rotor speed $(4500 \mathrm{r} / \mathrm{min})$ and the nozzle speed $(12500 \mathrm{r} / \mathrm{min})$ were set to constant. The $\mathrm{E}_{23}$ group has a $\mathrm{D}_{\mathrm{V} 10}$ of $70.81 \mu \mathrm{m}$, a $\mathrm{D}_{\mathrm{V} 50}$ of $120.36 \mu \mathrm{m}$, a $\mathrm{D}_{\mathrm{V} 90}$ of $178.08 \mu \mathrm{m}$, a $F_{23}$ group of $D_{\mathrm{V} 10}$ of $72.21 \mu \mathrm{m}$, a $D_{\mathrm{V} 50}$ of $119.55 \mu \mathrm{m}$, and a $D_{\mathrm{V} 90}$ of $174.94 \mu \mathrm{m}$. Comparing the particle size of the two groups, it can be seen that there was no significant change in the particle size of the $E_{23}$ group compared with the $F_{23}$ group, so the two do not appear relevant.

\subsection{Overall regression analysis}

IBM SPSS Statistics 24 (IBM, Armonk, NY, USA) software $^{[29,30]}$ was applied to regression analysis to obtain significant effects of the three variables on sedimentation and droplet size, the results are shown in Tables 5 and 6.

Table 5 Correlations between different spray height, nozzle speed and rotor speed and droplet deposition $(\alpha=0.05)$

\begin{tabular}{lccc}
\hline \multicolumn{1}{c}{ Source of difference } & Spray height & Nozzles speed & Rotor speed \\
\hline Correlation coefficient & 0.540 & 0.304 & 0.181 \\
P-value & 0.040 & 0.292 & 0.522 \\
\hline
\end{tabular}

According to the regression analysis results in the table, the correlation coefficients of spray height, nozzle rotation speed and rotor rotation speed and droplet deposition are 0.540, 0.304 and 0.181 respectively. Among the three factors, the spray height $P<0.05$, suggesting that spray height has a remarkable effect on the 
droplet deposition. During the spraying of the droplets, the increase of the spray height guarantee the droplets a longer free movement time, which creates an opportunity for the drift of the droplets, so the proper spray height is extremely critical.

Table 6 Correlations between different spray height, nozzle speed and rotor speed and droplet size $(\alpha=0.05)$

\begin{tabular}{lccc}
\hline Source of difference & Spray height & Nozzles speed & Rotor speed \\
\hline Correlation coefficient & 0.002 & 0.292 & 0.309 \\
P-Value & 0.854 & 0.021 & 0.034 \\
\hline
\end{tabular}

From the regression analysis results in the table, the correlation coefficients of the three variables of spray height, nozzle rotation speed and rotor speed and droplet diameter are 0.002, 0.292, and 0.309 respectively. The spray height $P>0.05$, the effect on the droplet size is not significant, and the nozzle speed and rotor speed $P<0.05$, the impact on the droplet size and the width of the droplet spectrum is significant. After the droplets are formed, the particle size has been fixed and will not be affected by the spray height. As the nozzle speed increases, the tangential force causes the droplets to further break and the droplet size becomes smaller. In addition, as the rotational speed of the rotor increases, the wind field strength increasing in the area of the droplet movement smaller the droplet size, indicating that the droplet is further broken by the action of the wind force.

\section{Conclusions}

1) The spray performance comprehensive experimental platform and laser particle size analyzer were applied to explore the droplet deposition amount and droplet size under different spray heights, nozzle rotation speeds and rotor speeds. The results show that the spray height has a notable effect on the deposition amount, but its influence on the droplet size is negligible. The nozzle rotation speed and rotor rotation speed have an extraordinary effect on the droplet size, but have a not striking effect on the deposition amount.

2) Experiment shows that the phenomenon of droplet drift occurs obviously and all the effective deposition rates below $75 \%$ in the case of the above test parameters.

3) The practical spray effect of the plant protection UAV is also affected by environmental factors such as natural wind speed, temperature and humidity. The next step will be to build a UAV flight experiment platform and add environmental factors for related experiment.

\section{[References]}

[1] Liu C, Men W, Liu y, et al. The pollution of pesticides in soils and its bioremediation.System Sciences and Comprehensive Studies in Agriculture 2002, 18(4): 291-292. doi: 10.3969/j.issn.1001-0068.2002.04.015.

[2] Wang J, Li Y, Wang X, et al. Status quo of pesticide use in China and its outlook. Agricultural Outlook, 2017, 13(02): 56-60. doi: 10.3969/ j.issn.1673-3908.2017.02.012.

[3] Chen X, Wang C, Bo R. Current situation of Chinese pesticide application and policy suggestions. Pesticide Science and Administration, 2016, 37(2): 4-8. doi: 10.3969/j.issn.1002-5480.2016.02.002.

[4] Yuan H, Yang D, Yan X, et al. Pesticide efficiency and the way to optimize the spray application. Plant Protection, 2011, 37(5): 14-20. doi: 10.3969/j.issn.0529-1542.2011.05.002.

[5] Lu J, Chen J, Wu Y, et al. Spray performance study of rotating speed and levels wind on spray of electrostatic sprayer. Journal of Agricultural Mechanization Research, 2019, 41(07): 35-41. doi: 10.3321/j.issn:10026819.2005.01.042

[6] Al M, Douzals J, Sinfort C, et al. Influence of nozzle type, nozzle arrangement and side wind speed on spray drift as measured in a wind tunnel. Ageng, 2014. doi: 10.13140/2.1.4820.1606

[7] Holterman H J, Van De Zande J C, Porskamp H A J, et al. Modelling spray drift from boom sprayers. Computers and electronics in agriculture, 1997, 19(1): 1-22. doi: 10.1016/S0168-1699(97)00018-5

[8] FRANZ, E., et al. Aerial spray deposit relations with plant canopy and weather parameters. Transactions of the ASAE, 1998, 41.4: 959. doi: $10.13031 / 2013.17253$

[9] Dorr G, Hanan J, Adkins S, et al. Spray deposition on plant surfaces: a modelling approach. Functional Plant Biology, 2008, 35(9): 988-966. doi: 10.1071/FP08056

[10] Zhang H, Dorr G, Zheng J, et al. Wind tunnel experiment of influence on droplet size distribution of flan fan nozzles. Transactions of the CSAE, 2012, 43(6): 53-57. doi: 10.6041/j.issn.1000-1298.2012.06.010

[11] Thistle H W, Teske M E, Droppo J G, et al. AGDISP as a source term in far field atmospheric transport modeling and near field geometric assumptions. ASAE Annual Meeting, 2005. doi: 10.13031/2013.19778

[12] Thomson S J, Womac A R, Mulrooney J E. Reducing pesticide drift by considering propeller rotation effects from aerial application and near buffer zones. Sustainable Agriculture Research, 2013, 2(3): 41-51. doi: 10.22004/ag.econ.230554

[13] Shen A, Zhou S, Wang M, et al. Simulation and analysis of Multi-rotor UAV flow field. Transactions of the CSAM, 2018, 36(4): 29-33. doi: 10.13645/j.cnki.f.d.20180208.012

[14] Nuyttens D, De Schampheleire M, Baetens K, et al. Drift from field crop sprayers using an integrated approach: Results of a five-year study. Transactions of the ASABE, 2011, 54(2): 403-408. doi: $10.13031 / 2013.36442$

[15] Lv X, Fu X, Wu P, et al. Influence of spray operating parameters on Droplet Deposition. Transactions of the CSAE, 2011, 42(6): 70-75. doi 10.3969/j.issn.1000-1298.2011.06.014

[16] Ru Y, Jin L, Zhou H, et al. Performance experiment of rotary hydraulic atomizing nozzle for aerial spraying application. Transactions of the CSAE, 2014, 30(3): 50-55. doi: 10.3969/j.issn.1002-6819.2014.03.007

[17] $\mathrm{Yu} \mathrm{H,} \mathrm{Li} \mathrm{J,} \mathrm{Dong} \mathrm{Y,} \mathrm{et} \mathrm{al.} \mathrm{Plant} \mathrm{protection} \mathrm{design} \mathrm{of} \mathrm{UAV} \mathrm{spray}$ performance comprehensive experimental platform. Times Agricultural machinery, 2016, 43(9): 38-40. doi: 10.3969/j.issn.1007-8320.2016.09.023

[18] Lan Y, Peng J, Jin J. Research status and development of pesticide spraying droplet size. Journal of South China Agricultural University, 2016, 37(06): 1-9. doi: 10.7671/j.issn.1001-411X.2016.06.001

[19] Zhou Q, Xue X, Application status and research direction of nozzles in aviation spray. Journal of Chinese Agricultural Mechanization, 2016, 37(10): 234-237. doi:10.13733/j.jcam.issn.2095-5553.2016.10.049

[20] Guan X, Qu B, Ou M, et al. Measurement experiments of particle size spectra and velocity field of three kinds of small flow nozzles. Journal of Chinese Agricultural Mechanization, 2014, 35(5): 71-76, 80 . doi: 10.13733/j.jcam.issn.2095-5553.2014.05.017

[21] Zhang H, Zheng J, Zhou H, et al. Performance experiments of rotary cage atomizer for biological pesticide application. Transactions of the CSAE, 2013, 29(4): 63-70. doi: 10.3969/j.issn.1002-6819.2013.04.008

[22] General Administration of Quality Supervision, Inspection and Quarantine of the People's Republic of China, standardization administration of China. Particle size analysis-Laser diffraction method: GB/T 19077-2016. Beijing: standards press of china, 2016.

[23] Civil Aviation Administration of China. Quality indexes of agriculture aviation operation-Part 1-Spraying operation: MH/T 1002.1-2016[S].

[24] Civil Aviation Administration of China. Design specification for spraying equipment of aircraft: MH/T 1049-2012. 2012.

[25] Qi L, Fu Z. Experimental study on spray deposition uniformity. Transactions of the CSAE, 1999, 15(2): 107-111. doi: 10.3321/ j.issn:1002-6819.1999.02.023

[26] Jia W, Li P, Qiu B, et al. Experimental study on droplet size and velocity distribution of agricultural electrostatic spray. Transactions of the CSAE, 2008, 24(2): 17-21. doi: 10.3321/j.issn:1002-6819.2008.02.004. doi: 10.13675/j.cnki.tjjs.2018.05.010

[27] Wang K, Yang G, Li P, et al. Simulation on liquid films impact atomization process of adjacent pressure swirl injectors. Journal of propulsion technology, 2018, 39(5): 1041-1050. doi: 10.13675/ j.cnki.tjjs.2017.02.020

[28] Lu J, Chen J, Wu Y, Wang B. Spray Performance Study of Rotating 
Speed and Levels Wind on Spray of Electrostatic Sprayer. Journal of Agricultural Mechanization Research, 2019, 41(07): 35-41. doi: 10.13427/j.cnki.njyi.2019.07.007

[29] Deng Z, Yu P ,Chen L. Application of SPSS software in orthogonal design and result analysis. Computer Study, 2009(05): 15-17. doi: 10.3969/j.issn.2095-2163.2009.05.007

[30] Chen S, Lan Y, Bradley K F, et al. Effect of wind field below rotor on distribution of aerial spraying droplet deposition by using multi-rotor UAV. Transactions of the CSAE, 2017, 48(8): 105-113. doi: 10.6041/ j.issn.1000-1298.2017.08.011 